\title{
Writing a Research Article in an Introductory Course
}

\author{
William O'Brochta* \\ Department of Political Science \\ Washington University in St. Louis
}

\begin{abstract}
How well can students exposed to political science for the first time write a research article? Previous research has introduced selected research article writing skills to students in introductory courses, but has not studied whether students in such courses can produce a full research article. I re-designed an Introduction to Comparative Politics course based on the research article writing process. I hypothesized that students would make major gains in article writing skills and develop proficiency comparable to experienced majors. Using a pre- and post-test design along with rubrics for each research article component, I found support for my hypotheses. Students reported large increases in confidence and ability to handle research article writing tasks as a result of the course and demonstrated proficiency comparable to majors on more than two-thirds of rubric items. I provide some suggestions for ways to implement parts of this course design in traditional introductory course settings.
\end{abstract}

Keywords: writing across curriculum, research design, introductory course. (7500 Words)

*Ph.D. Candidate, obrochtawj@wustl.edu, williamobrochta.net. I especially thank Julia Johnson and Meg Gregory for their exceptional help at all stages of this study. Eugene Kim, Max Lyon, Lisa McLellan, Sunita Parikh, Guillermo Rosas, and Julie Speer all provided useful comments and support. The Teaching Center at Washington University in St. Louis provided generous travel support. 
To what extent are students able to write their own research article in an introductory political science course? This project aims to bring the scientific process in political science to students who are being exposed to political science concepts and research for the first time. Instead of relegating undergraduate research to upper-level coursework, I suggest that students in an introductory course will be able to think and work through the research process surprisingly proficiently. Research design and writing skills are critically under-supplied in the political science major. Whereas students may be exposed to research methods courses later in their major career, most political science majors both lack experience with research design and article writing and need this experience in order to do well in future courses, a capstone or senior thesis, and in jobs where systematic social science ways of thinking are valued. I develop an intervention to addresses this need via a research article writing focused Introduction to Comparative Politics course. ${ }^{1}$

Recent revisions to the political science major have highlighted the importance of students participating in the research article writing process. However, students' first experiences doing undergraduate research typically occur in a senior capstone course at the end of a student's career as an undergraduate (Hummer, 2014). While such a course is certainly helpful in synthesizing knowledge accrued throughout the major, students often struggle to both learn how to do research for the first time and to produce high-quality work deemed acceptable for their capstone. A solution to this problem has been to move research methods instruction (statistical and, occasionally, qualitative analysis) to a separate course required before students enter their senior year (Bernstein and Allen, 2013). In these courses, instructors tend to prioritize learning how to conduct statistical analysis in a particular software package over teaching students to develop theoretical arguments and ask compelling research questions (Leston-Bandeira, 2013).

Numerous scholars have suggested moving research design and writing topics to substantive courses so that students have the opportunity to practice these skills before writing a

\footnotetext{
${ }^{1}$ This study was approved by the Institutional Review Board, \#201112140.
} 
capstone paper (Bergbower, 2017; Bos and Schneider, 2009; Medvedeva and Recuber, 2016; Olsen and Statham, 2005; Siver, Greenfest and Haeg, 2016). This makes sense because developing writing acumen is an iterative process that requires extended practice (Sommers and Saltz, 2004). I extend this argument by suggesting that introductory political science courses are an ideal place to introduce the research process of professional political scientists and to involve students as colleagues in this process. In doing so, I combine piecemeal approaches to teaching research design in introductory classes from political science with a well-developed and successful emphasis on first-year undergraduate research in the hard sciences. Political scientists have integrated various parts of the research process into introductory courses and have generally found that students are successful in learning research concepts and applying them (Bob, 2001; Blings and Maxey, 2017; Dickovick, 2009; Franklin, Weinberg and Reifler, 2014; Olsen and Statham, 2005; Williams, Goodson and Howard, 2006). Guiding students through writing their own research article is just a more comprehensive and holistic way to synthesize the research design and writing skills that others have had success teaching in parts (Sherman and Waismel-Manor, 2003; see also Ishiyama, 2002). This integrative approach has formed the basis for rich research collaborations in many science disciplines (Carson and Miller, 2013; Harrison et al., 2011; Jordan et al., 2014).

Early exposure to research article writing skills will help students better tackle future writing assignments and to develop social science research skills that are critical to many professions (Bernstein and Allen, 2013; Ishiyama and Breuning, 2003; Sommers and Saltz, 2004; Zeiser, 1999). Introductory courses also attract many non-political science majors, so such a course may be the only opportunity to expose students from other disciplines to political science research.

As a potential side benefit, involving students in the research process increases interest in the discipline (Carson and Miller, 2013; Harrison et al., 2011; Jordan et al., 2014; Scheel, 2002; Wenk and Tronsky, 2011). By working through the political science research process, students can better understand that political scientists do not memorize facts about different 
countries, rather they search for answers to salient questions of governance, questions to which students themselves can contribute answers.

I taught a re-designed Introduction to Comparative Politics course to nine students at a medium-sized private Midwestern university in Summer 2019. This course exposed students to typical topics in comparative politics, but structured coursework around students completing all the components of a research article save the actual analysis. I hypothesized that student confidence and ability to perform research article related tasks would increase as a result of the course and that students would be proficient at these tasks when compared to published undergraduate work in the field. I measured self-reported student confidence and demonstrated ability using a pre- and post-test design and evaluated student proficiency using rubrics for each component of the research article. Results suggest support for both hypotheses: student confidence and ability to perform research article related tasks increased and students completed these tasks surprisingly proficiently. Though this intervention represents a significant departure from the design of many introductory political science courses, I provide suggestions for ways instructors teaching larger courses in a more standard format could introduce research article writing to their students.

\section{Course Background and Structure}

I taught a research article writing focused Introduction to Comparative Politics course at a medium-sized private Midwestern university in summer 2019. While the political science department maintains consistency in the way core courses are taught during the spring and fall semesters, the small and diverse student body enrolled in summer semester courses offered an opportunity to implement a re-designed course focused on research article writing. 


\section{Student Characteristics}

The typical Introduction to Comparative Politics course at this university enrolls about 100 students and follows a standard format of two hours of professor led lecture and one hour of an undergraduate teaching assistant led discussion section per week. The course uses a popular comparative politics textbook and follows a relatively typical structure common to many Research 1 universities. ${ }^{2}$ Students are assessed entirely on the combination of three multiple choice exams, multiple choice homework problems, and true/false or short answer pop quizzes. During the course, students are exposed to political science research through textbook in-text citations; they are not required to read research articles. Students do not complete writing assignments in the course.

The modal student enrolled in the course is a college freshman with one of many possible majors. The course fulfills a requirement for the political science major as well as a distribution requirement for students in other majors. Freshman major choices are relatively flexible: even though many freshman declare a major upon entering the university, most are still unsure of their major, and their minds may be changed as a result of a first course in any particular discipline.

This course was significantly smaller (nine students) and met more frequently in a condensed time period (eight contact hours per week for five weeks). Table 1 displays demographics of the students in the course and their perceived experience with several research article writing topics. Gender and ethnic diversity were fairly representative of the student body as a whole. Summer classes allow enrollment from selected high school seniors; about half of enrolled students were underclassmen or in high school whereas half were upperclassmen. This represents a larger enrollment from upperclassmen than is typical for an introductory political science course.

\footnotetext{
${ }^{2}$ I examined Research 1 universities listed on collegefactual.com's Best Political Science schools list. Twelve of the top schools had syllabi available for review. The average class size was 146 students; all twelve courses were taught with two lectures and one discussion section per week. Most used a well-known comparative politics textbook. Eight included some writing component, though only one focused on research design.
} 
Table 1: Demographics and Prior Experience

\begin{tabular}{cc}
\hline Measure & Mean \\
\hline Demographics & \\
\hline Female & 0.44 \\
Ethnic Minority & 0.33 \\
High School & 0.22 \\
Freshman/Sophomore & 0.22 \\
Junior/Senior & 0.56 \\
Enrollment Required & 0.44 \\
Enrollment Interested & 0.66 \\
No Previous PS Classes & 0.56 \\
PS Major & 0.33 \\
AP Classes & 7 \\
\hline Pre-Test Experience & \\
\hline Reading an Article & 3.33 \\
Reading PS Article & 1.67 \\
Conducting PS Literature Search & 1.56 \\
Writing a PS Research Question & 1.56 \\
Writing a PS Theoretical Argument & 1.33 \\
\hline
\end{tabular}

Self-reported information from nine students. Pre-Test Experience scored from 1 (none) to 5 (high).

Sixty-six percent of enrolled students reported that the reason they enrolled was due to intellectual curiosity or personal interest whereas $44 \%$ enrolled because the course fulfilled either a major or distribution requirement. The majority of students had taken no previous political science courses and were not majors. Indeed, student majors ranged from Neuroscience to Finance to Psychology. Students reported taking a substantial number of Advanced Placement classes in high school, which is an indicator of high academic achievement.

I gauged student experience as part of a beginning-of-semester pre-test (scored from 1 indicating no experience to 5 indicating extensive experience). Though students did report a moderate amount of experience reading research articles in disciplines other than political science, experience with political science research article writing was quite low. In particular, though a few students said they had read a political science article, students had virtually know experience with the research process in political science. Lack of knowledge 
was expected given the diversity of student majors and lack of exposure to political science courses. However, it is noteworthy that reported experience among the two political science majors who had already taken courses in the discipline was not dramatically higher than the reported experience from the other students. This suggests that these majors had not learned research article writing skills, perhaps because one of the only opportunities to do so is during an optional senior capstone.

Though the demographics and experiences of students enrolled in this course are relatively similar to the typical student enrolled in the course during the spring or fall semesters, course size and the number of contact hours per week are vastly different. This is part of the reason that I focus on student improvement and perceptions of abilities throughout this summer course and leave direct comparisons between the typical course structure and the research writing structure implemented here for future research.

\section{Course Structure}

This course was structured in modules, where each module corresponded to a particular research article writing skill. Throughout a module, students were introduced to a skill and then asked to produce a version of the skill based on their own research interests. The modules corresponded directly to the way a typical research article is written. As such, students cumulated their work, incorporating and improving their work from previous modules into their work for future modules. Modules included: research question, annotated bibliography and literature review, theory and hypothesis, and research design. At the end of the semester, students had produced a complete research article that included the components listed above plus an abstract, introduction, and conclusion. Since teaching students research methods was not part of the course, students had the option to speculate about potential results, but no formal data analysis was required.

Each module was structured to help students learn the skills they needed to produce a research article for their own research project at the end of the module. Every class meeting 
focused on a substantive and a research article writing skill (herein "methods") topic. Prior to a given class, students read a research article and wrote a reading journal that responded to prompts about both substantive and methods topics. ${ }^{3}$ Students also read parts of a research article writing guide for each module. ${ }^{4}$ Instructional time was roughly split between activities and discussion related to substantive and methods topics. In the methods focused parts of class, students engaged directly with the article they had read, identifying strengths and weaknesses of the ways in which the author(s) addressed the methods topic. Students also worked to revise the author(s) work and engaged in discussions about best practices for the particular methods topic. For example, before the theoretical argument was due, students read articles that I selected specifically to help them craft their theory sections. One such article listed numerous hypotheses with little justification for any of them. This article helped to structure a class activity related to identifying a key hypothesis. Similarly, a well-known article about bureaucracy presented a simple and clean causal chain clearly derived from previous work that students used as a model to theorize about similar research questions.

Toward the end of a module, students turned in their own version of the skill learned in the module (e.g. a theory for the theory module). One class in each module was devoted to a "Methods Workshop" where students discussed their work in a collaborative environment. For the theory module, the Methods Workshop involved spending some time in groups discussing students' theoretical arguments before introducing core ideas related to research designs. Students then rotated in groups around the classroom discussing which research method would be best for their project, using Internet resources to find data sources, and discussing alternative mechanisms. Since student research questions were diverse, frequent rotation ensured that core course topics were mentioned and synthesized repeatedly.

Methods Workshops were followed by a more formal peer review and comments from the instructor. Students had the opportunity to turn in a revised version of their work based on

\footnotetext{
${ }^{3} \mathrm{~A}$ pre-module addressed reading and understanding research articles.

${ }^{4}$ I used Lisa Baglione's excellent Writing a Research Article in Political Science.
} 
the comments they received if they wished to improve their grade. Otherwise, students were expected to revise their work and to include it in future versions of their research article.

\section{Learning Goals, Hypotheses, and Measurement}

I had two related learning goals for this course. First, I wanted to assess student progress in learning research article writing skills throughout the course. This was similar to a "can they do it" intervention, where the key metric was whether there was any improvement in writing skills as a result of the course. A second goal was to measure "how well can they do it" by assessing student proficiency at producing each part of the research article. Importantly, the second learning goal is not wholly conditional on the first: students could be proficient at developing certain parts of their article at the same time they struggled to demonstrate overall improvement in writing skills. Thus, the first learning goal identified overall improvement, while the second goal highlighted skills that students demonstrated particularly well.

\section{Improvement from Pre-Course}

Previous research related to article writing in political science has found that student ability to perform research related tasks generally increases over the course of a semester. I argue that in a course that emphasizes research design and writing skills more generally, student outcomes should also improve from the beginning to the end of the course.

Hypothesis 1: Student ability to perform research article writing related tasks will increase as a result of taking the course.

To test this hypothesis, I administered a pre- and post-test with a common battery of test questions. Students were given the pre- and post-tests as assignments that they 
completed at home so that they did not have to rush to complete the survey, though an estimated completion time was suggested. The common battery consisted of two main components: a confidence section and an applied section. The confidence section asked students to evaluate "How confident are you in your abilities to do the following" where numerous statements were listed, and responses were coded on a Likert scale from 1 (low) to 5 (high). These statements related to students' perceived ability to conduct research related tasks. Statements included: "Identifying the key points in a political science research article" and "Developing testable hypotheses" among others (Bernstein and Allen, 2013; Bos and Schneider, 2009). The confidence measures indicated both exposure to the skills described and perceived ability to perform these skills on an exam or in a paper.

After prolonged exposure to all of the topics and skills covered in the confidence measures as a result of the course, students' confidence should increase in the post-test compared to the pre-test. To evaluate this, I recorded the pre- and post-test responses and conducted a paired $t$-test with the null hypothesis that the pre-test and post-test results were the same. I expected that the post-test mean would be significantly greater than the pre-test mean.

During the applied section, students were asked to read a short research article and to answer several questions about the article. These questions included descriptive information related to article comprehension such as identifying the research question, hypotheses, and empirical strategy and discussing whether the design choices the author made were appropriate. Perhaps more importantly, I then asked students to build on what they learned in the article, identifying their own research question related to the article and describing possible relevant literature, hypotheses, and data (Wenk and Tronsky, 2011). I selected two articles for students to read: one for the pre-test and one for the post-test to eliminate the possibility of students recalling previous answers. I matched the length and perceived complexity of the articles as best as possible; both articles were approximately 4,000 words and were published in Research $\mathscr{G}$ Politics. ${ }^{5}$

\footnotetext{
${ }^{5}$ The pre-test article was "The longevity of national identity and national pride: Evidence from wider Europe" by Valentina Dimitrova-Grajzl, Jonathan Eastwood, and Peter Grajzl, 2016. The post-test article
} 
These open-ended responses were evaluated based on a simple rubric from 1 (needs improvement) to 5 (outstanding). I recorded the pre- and post-test scores and conducted a paired $t$-test with the null hypothesis that the pre-test and post-test results were the same. I expected that the post-test mean would be significantly greater than the pre-test mean.

\section{Proficiency}

Throughout the course, I was interested in how well students grasped particular research article writing skills. Based off of previous work related to undergraduate research in the hard sciences, I argue that a substantial proportion of students in the course will be able to gain a capable grasp of these concepts and be able to produce competent versions of each component of a research article.

Hypothesis 2: The class will demonstrate "proficient" ability to produce a research article.

The empirical focus here was on the end-of-module assignments that students turned in applying the module's concepts to their own research project. ${ }^{6}$ Each assignment was evaluated based on a rubric provided to students at the beginning of the semester. This rubric aligned with the checklists listed in the research article writing book that students read. Rubrics were split into three categories: "needs improvement," "proficient," and "outstanding" with point values assigned to each category. In order to evaluate students' grades, I considered "outstanding" work to be that where students clearly made a strong effort to demonstrate a rubric skill.

After the semester concluded, I re-evaluated student work using the same rubric, but using a different definition of "outstanding" work. Here "outstanding" meant that students demonstrated a skill to a degree beyond that of research published in The Pi Sigma Alpha

was "The impact of foreign fighters on civil conflict outcomes" by Tiffany Chu and Alex Braithwaite, 2017.

${ }^{6}$ I examined student submissions at the end of each module, not the fully revised version of the article turned in at the end of the semester. 
Journal of Politics, the main peer-reviewed undergraduate research journal in political science. "Proficient" meant that students demonstrated a skill at a level roughly comparable to research published in this journal.

I chose to use the rubrics in these two ways in order to both encourage and reward students for their best attempts at each assignment during the semester while also being able to evaluate students against a high bar of competency relative to more advanced students in the discipline. I argue that even students exposed to political science for the first time will be able to demonstrate "proficient" research article writing skills when compared to published undergraduate work. To assess this hypothesis, I scored each rubric skill relative to published undergraduate work, where "needs improvement" was given a 0, "proficient" was given a 1, and "outstanding" was given a 2. I deemed the class "proficient" in a given competency if $80 \%$ of students scored at or above "proficient" on a given competency (\% Proficient). ${ }^{7}$ I hypothesize that $\%$ Proficient will exceed $50 \%$ for all parts of the research article.

\section{Results}

\section{Improvement from Pre-Course}

Table 2 displays results from the confidence and applied sections of the pre- and post-test. Also displayed are questions from the post-test regarding students' perceived importance of the research article writing assignments. I report pre- and post-test mean confidence and applied scores along with $t$-values and $p$-values from paired $t$-tests. Student confidence increased by a significant amount across all aspects of the research article writing process, supporting Hypothesis 1. In the pre-test, students reported low confidence; confidence increased to relatively high confidence in the post-test. Students in the pre-test were slightly

\footnotetext{
${ }^{7}$ Five students consented to participate in this part of the study, so the $80 \%$ figure represents four of the five being "proficient."
} 
more comfortable identifying the key points of articles and writing research questions compared to other skills. They also reported a moderate level of ability to understand the purpose of political science. After the semester ended, confidence in all measures increased. In particular, students almost universally reported a high level of understanding the purpose of political science and confidence in writing research questions, defining variables, and understanding different research methods. It is also noteworthy that students increased their identification as social scientists, given the diverse majors present in the course.

Table 2: Pre- and Post-Tests Show Improvement in Confidence and Applied Skills

\begin{tabular}{|c|c|c|c|}
\hline Measure & Pre-Test Mean & Post-Test Mean & $t$-value ( $p$-value) \\
\hline \multicolumn{4}{|c|}{ Reported Confidence } \\
\hline Identifying Article Key Points & 2.33 & 4.00 & $5.77(0.00)$ \\
\hline Writing Research Questions & 2.33 & 4.44 & $8.10(0.00)$ \\
\hline Identifying Literature & 2.11 & 4.00 & $5.38(0.00)$ \\
\hline Choosing Sources & 2.00 & 3.89 & $4.46(0.00)$ \\
\hline Developing Hypotheses & 2.22 & 3.89 & $3.78(0.01)$ \\
\hline Defining IV/DV & 2.00 & 4.44 & $8.32(0.00)$ \\
\hline Choosing Research Design & 1.44 & 3.89 & $5.50(0.00)$ \\
\hline Writing Research Article & 1.44 & 3.78 & $8.08(0.00)$ \\
\hline Understand Purpose of PS & 3.22 & 4.78 & $4.13(0.00)$ \\
\hline Understand PS Research Methods & 2.22 & 4.11 & $4.86(0.00)$ \\
\hline Identify as Social Scientist & 2.00 & 3.33 & $8.00(0.00)$ \\
\hline \multicolumn{4}{|c|}{ Applied Skills } \\
\hline Article Summary & 2.50 & 4.00 & $3.00(0.02)$ \\
\hline Research Question & 2.25 & 4.38 & $5.34(0.00)$ \\
\hline Literature Ideas & 2.13 & 3.88 & $3.86(0.01)$ \\
\hline Hypothesis & 2.88 & 4.75 & $4.26(0.00)$ \\
\hline Data and IV/DV & 2.86 & 4.13 & $3.87(0.01)$ \\
\hline \multicolumn{4}{|c|}{ Importance of Research Article in... } \\
\hline Applying Course Ideas & & 4.25 & \\
\hline Increasing Course Involvement & & 4.13 & \\
\hline Bringing in Interests & & 4.13 & \\
\hline Exploring New Ideas & & 4.50 & \\
\hline
\end{tabular}

Results from pre- and post-tests. Confidence and importance are self-reported; applied skills questions were free responses scored on a rubric. $t$-value is from a paired $t$-test with the $p$-value in parentheses. Sample size is nine students.

The applied skills section of Table 2 indicates that reported increases in confidence were mirrored by increases in student ability to demonstrate article writing skills, further sup- 
porting Hypothesis 1. In the pre-test, article summaries were frequently too brief and missed key points of the article. The new research questions students wrote were vague and the literature they identified as relevant to studying their research questions was highly derivative of the article they read. Hypotheses were not falsifiable, nor were they specific and testable. Ideas about data to test their hypothesis and specifications of independent and dependent variables were again very similar to the structure of the article they read.

In the post-test, article summaries were more focused on key ideas. Research questions and especially hypotheses followed the structures taught in class and variables were defined more precisely. Students still had some trouble identifying a good list of relevant literature, but this difficulty was not mirrored in their actual research articles. Finally, students recognized the importance of the research article writing assignments in different aspects of the course.

\section{Proficiency}

I now move to testing how proficient students were at completing each part of the research article. Table 3 displays the five rubrics used to evaluate students as well as an overall average. The five rubrics consisted of 68 individual skills. Each student received a score of 0,1 , or 2 on each skill. If at least $80 \%$ of students received a 1 or higher the class was considered "proficient" at this skill. The \% Proficient column displays the percentage of skills on a given rubric that students performed proficiently. In all cases, \% Proficient exceed 50\%, so Hypothesis 2 was supported. The Average Score column displays the average student score across skills on a given rubric. The Average Score ranged from 0.80 to 0.90 . This indicates that most students received a score of "proficient" on most of the skills with a few "needs improvement" scores.

The final two columns in Table 3 break the rubric skills in \% Proficient into two categories: structure refers to rubric skills that students could demonstrate proficiency in by following a template or formula (e.g., an "if/then" hypothesis) whereas content rubric skills 
Table 3: Class Was Proficient on the Majority of Rubric Skills

\begin{tabular}{ccccc}
\hline Article Component & \% Proficient & Average Score & Structure $\%$ & Content \% \\
\hline Research Question & 67 & 0.83 & 100 & 50 \\
Literature Review & 77 & 0.80 & 88 & 67 \\
Theory & 83 & 0.90 & 100 & 67 \\
Research Design & 71 & 0.83 & 100 & 67 \\
Intro, Abstract, Conclusion & 79 & 0.83 & 100 & 73 \\
Overall & 78 & 0.84 & 96 & 67 \\
\hline
\end{tabular}

Results from student submissions scored using rubrics. \% Proficient is the percentage of rubric skills at least $80 \%$ of students completed proficiently. Average Score is the average rubric score on a scale from 0 to 2 . \% Structure and \% Content break out \% Proficient by type of skill. Sample size is five students.

lacked this cut-and-paste approach. Thirty-four percent of rubric skills were based on structure. Students demonstrated a high level of proficiency fulfilling structural rubric skills. Proficiency in content based skills was substantially lower than for structure skills, but students still demonstrated proficiency in two-thirds of content related skills. This break-down suggests that students exposed to political science skills for the first time are quite adept at applying structural rules or formulas to their work. That is, once taught about ways in which to structure a hypothesis, students quickly learned how to write effectively structured hypotheses for themselves. Students may be more familiar with learning structural skills, as many high school courses involve assessments based on memorization.

Though content proficiency was lower, students demonstrated impressive proficiency with content related skills. In what follows, I describe some of the skills that students succeeded in and others that they struggled to complete in order to present a clearer picture of the types of skills students were able to learn in the course. The evidence in the rest of this section comes from a combination of student proficiency on rubric tasks and a series of informal evaluations where students discussed their perceptions of their progress in the course.

Students reported that getting started and writing the research question and literature review were both very challenging. These challenges were compounded by the fact that the short duration of the course meant that the research question was due at the beginning of 
the second week of class and the literature review was due at the beginning of the third week. Because this was most students' first exposure to political science, they struggled to understand the scope of the discipline and to figure out how their question fit into the political science literature. These challenges were partially compensated by students' high levels of interest in big political science questions. We conducted several activities in class to conceptualize the entire discipline and to work to identify research questions that were relevant to students and to public policy; without these two connections, students felt that research questions were not worth such a large investment of their time.

One student's initial research question was "Why does the KMT support cross-straight relations with the CCP?" This question was too specific, does not clearly fit into political science literature, and is not falsifiable. During the individual meetings I conducted with students after they turned in their research questions, I learned that this student was interested in Taiwan-China relations and that this interest prompted his research question. With a little work thinking about framing and ways to make his question puzzling, the student successfully altered his research question to examine the extent to which within country-level factors drive relations between democracies and authoritarian regimes.

A second student's initial research question began as a puzzle, but morphed over time. She asked, "Why are highly educated individuals susceptible to scientific misinformation in political contexts?" After some assistance finding sources in the existing literature, she realized that studies have shown that highly educated individuals are not more susceptible to misinformation than other people. However, she then identified a possible contribution the stakes people have in correctly identifying factual information - and used this to create a more nuanced and novel research question hypothesizing that highly educated individuals will be less susceptible to misinformation compared to less educated individuals specifically when the stakes are high.

In both cases, the student's initial research question changed significantly from the first time they wrote it until they turned in their theoretical argument. Since students were new 
to political science literature, they had little to build on initially, but this weakness fixed itself as students clarified their ideas as we worked through the literature review writing process.

I asked students to turn in both an annotated bibliography and a literature review. Literature reviews are difficult for many scholars to construct, and they were particularly challenging for students who lacked all the component skills necessary to even begin examining the literature. We devoted class time to learning how to read and summarize political science research articles, how to find and evaluate the usefulness and credibility of scholarly sources, and how to extract common themes from a set of sources. Perhaps surprisingly, both high school/underclassmen and upperclassmen were rather adept at finding appropriate sources, analyzing and grouping them, and discussing them in a literature review format.

Students tended not to clearly differentiate their research question from the existing literature in their literature review. One reason for this was a lack of confidence in their research question. I asked students to reflect on how they felt about their literature review, and more than half stated that they struggled a lot to write it and did not feel confident in the end product. This feeling is a somewhat logical result of asking students to read an immense amount of published work and then telling them to figure out how their work contributes to this literature. One preemptive step I took was to make clear to students that, by enrolling in the course, they were now political scientists and were qualified to engage the work of other scholars and to critique it. After diagnosing lack of confidence as an underling problem that manifested in literature reviews, I took reactive action and spent class time explaining the lengthy and convoluted process it took to publish one of my own articles. Student confidence and willingness to articulate their article's unique contribution improved after this activity.

Theoretical arguments were strong; this was aided by an emphasis on producing a "flow diagram" linking the independent and dependent variables along a causal pathway and addressing alternative explanations. Students worked with their diagrams several times in class 
and also diagrammed theoretical arguments from published work as an in-class activity. For most students, hypothesis writing was a straightforward exercise in simplifying their flow diagram.

At this point in the article writing process, students' work started to diverge more substantially. Some students had one simple and clear hypothesis, while others were trying to manage multiple hypotheses with complex causal explanations. This disjuncture resulted in some students with complex causal explanations trying to fit those explanations into a single, simple hypothesis. For example, one student hypothesized that a certain type of people would be "better able to determine risk surrounding a situation and re-evaluate their perception of misinformation." Her hypothesis implied that the independent variable would separately result in two dependent variables. However, her theoretical argument was that different types of people have different abilities to determine risk and that the ability to determine risk is really the independent variable that causes perceptions of misinformation. The hypothesis was quickly and easily corrected, but this highlights the ways in which students developing a theory for the first time may try to adopt the structure of examples discussed in class even if those structures do not match their argument.

The theory and research design sections of the article were timed to coincide with a inclass simulation called Policy Day. During Policy Day, students wrote briefing papers and simulated working in a legislature of a country randomly chosen at the beginning of the class to adopt policies related to their research articles. Policy Day built up the importance of the research article and its possible impacts in students minds while also teaching them the difficulties of translating academic work into legislation. This provided students with motivation to craft the best possible research design in order to be able to determine whether their policy would be effective.

Writing the research design also provided students with the opportunity to search for and explore existing data and measures. Though we discussed and read formal and normative theory early in the semester, I asked students to create an empirical research design. Since 
the class was not focused on implementing the research design, students worked to create the best possible design to test their hypothesis. Many students initially gravitated toward either one-time citizen surveys or country-level case studies. However, students were also quite interested in addressing causation and, after working through different research methods in class and reading a diverse set of published work, the majority of the class chose panel regression analysis or an experiment as the primary way to test their hypothesis. I asked students to propose and describe a primary and a secondary research method. This provided them with the opportunity to blend qualitative and quantitative methods along with methods that are better equipped to test causation. As a result of the brief introduction students received to each research method, some students had a difficult time articulating all the benefits and costs of the methods they chose. Similarly, students did consider how well their measures were able to test their hypothesis, but this discussion was often superficial.

As a final step, students wrote an introduction, abstract, and conclusion to their article. Even though they did not complete the actual analysis, I felt that it was important for students to leave the class with a fully written article that included all of the major components. Students did a good job developing a compelling introduction and summarizing their work in the conclusion. Conclusions were naturally more policy focused than in much published work because of the emphasis placed on policy both during Policy Day and throughout the course. Policy focused content in the conclusion did push out some discussion of future research and generalizability, both of which are a bit difficult to address without knowing the results of the study. Writing a compelling and concise abstract was challenging. We worked in class to write a complete abstract and to conduct a detailed peer review. This helped students get through the abstract writing process, but most abstracts could have been motivated more effectively.

Throughout the article writing process, students were asked to engage in peer reviews and to incorporate peer and instructor comments into revised versions of their article. The purpose of this was both to expose each student to the work of others in the class and to teach 
students how to refine their work and to provide effective feedback. The quality of peer review feedback was mixed, despite a handout and a discussion about ways to provide effective feedback. Part of the grade on each rubric was to incorporate previous peer and instructor feedback. Often students would receive good quality feedback and not fully implement it in revisions to their article. One potential reason was time. Students needed to quickly begin work on the next component of their article, and they knew that revisions to their previous article components made up at most $10 \%$ of their grade. The time issue may correct itself in a longer semester course. Another reason was that students were not fully comfortable receiving conceptual feedback instead of feedback on style or grammar that mimicked how they were assessed in high school. Peer reviewers were encouraged to mark grammar or style issues, but they were asked to mostly focus on content. A potential solution is to devote more class time early in the semester to revising article components based on feedback.

\section{Lessons for Larger Courses}

Overall, students increased their confidence and ability to complete research article writing tasks as a result of the course and demonstrated proficiency in more than two-thirds of rubric skills. Students also seemed to understand and appreciate the learning goals of the course. Few instructors will teach a core course like Introduction to Comparative Politics to such a small group of students over a condensed time period. However, I do believe that ideas from this course could travel to other course contexts.

In particular, instructors could teach a course that follows the research article writing process without having students write their own research article. Choosing to rely on published articles instead of a textbook or using articles to supplement a textbook can help improve article reading skills and help students learn about political science research. This alone can help ease the transition between introductory courses where readings, lectures, and assessments are often based on a textbook and most other political science courses that 
involve reading research articles. I have found that the key is to select articles that fully introduce core concepts before they conduct empirical analysis. Students reported that reading these types of articles allowed them to understand the basic concepts related to a topic and better prepared them to be engaged in class. For example, choosing an article that provides an overview of different regime types before focusing on patronage in presidential regimes prepares students to discuss all regime types and to think about patronage in other types of regimes. Selecting articles that combine fundamental concepts with empirical work often means that articles with fewer citations or that are published in lower impact journals are a better fit than articles in the top journals in the discipline.

Students reported that the reading journals held them accountable for reading assigned articles and provided them space to synthesize content and prepare for class discussion. Discussion forum posts, short quizzes, or peer activities are possible substitutes that provide some of these benefits in larger classes. Discussion forum posts allow for student interaction such that the instructor need not respond to each students' reflections on assigned articles. Short quizzes can be structured to ask open ended questions that emphasize content recall, synthesis, or student reflections. These quizzes could be paired with peer evaluation to reduce instructor grading time. Finally, instructors could design short activities for groups to complete at the beginning of a class period that revolve around key points from the reading as well as student reactions and reflections.

Exposing students to political science research will naturally lead them to ask their own questions and to seek to understand how political science research works. This presents an opportunity to design activities developing research questions, conducting literature searches, and designing a theoretical argument. Students can work in groups to practice the basics of these skills. Group work can occur in or out of the classroom. It may be helpful to let groups have some flexibility in the research questions that they develop. Assigning groups to all develop a theory based on the same research question teaches theory-writing skills, but misses an opportunity for students to fully engage with course content and to pursue their 
own interests.

Assessment in the course I taught was based on written assignments and student engagement (participation and peer reviews). Instead of traditional exams, groups worked to produce concept maps that synthesized core course concepts. This model relies on the instructor to provide frequent, written feedback to each student; in this case, I provided daily feedback on reading journals and at least twice-weekly feedback on article components. In larger classes, such a model may consume too much instructor time. One solution is to rely more heavily on peer evaluation and assessment using techniques outlined by Ishiyama and Watson (2014). In this model, group work can occur both in and out of the classroom with the instructor working with about ten groups. The combination of article writing groups and peer evaluation could easily scale this course format to forty or fifty students.

For courses in the 100 to 250 student range, exam based assessment may be more appropriate, but research article writing questions can be easily interspersed with content questions. Out-of-class group work could be eliminated in favor of frequent in-class group work that still provides students with the opportunity to practice article writing skills in a series of short activities instead of by writing a full research article. Use of technology can facilitate group "ticket out" writing assignments and provide instructors with a quick way to gauge and respond to student progress and understanding. Additionally, instructors can choose to provide a written evaluation for only a portion of these group writing assignments at any one time while still giving everyone credit for turning in the assignment.

\section{Discussion and Conclusion}

Student involvement in undergraduate research increases student interest and builds important skills that are useful for capstone projects and future careers. Previous work has introduced pieces of the research process to introductory courses, but scholars have yet to study how effectively students can learn the entire research design and article writing process 
in these courses. I taught a re-designed Introduction to Comparative Politics course that heavily emphasized a collaborative learning environment wherein students wrote their own research articles. I hypothesized that student ability to perform article writing tasks would increase as a result of taking the course and that students would be proficient at most article writing skills. Using a pre- and post-test and a set of rubrics, I found support for both hypotheses. Though these results occurred in a small class setting, I offer some suggestions for ways to teach research article writing skills in larger introductory courses.

The design of this study does not feature a control course with material taught in a more conventional manner. Comparing this intervention to a control would not make sense for testing the second hypothesis, since students in the control classroom would not complete any of the research article writing assessments. A pre- and post-test could be useful to gauge whether students picked up research article writing skills while reading a traditional textbook. This comparison did not take place at the university where the study was implemented because I felt that withholding an intervention that I believed would benefit students was not ethically ideal and traditionally taught Introduction to Comparative Politics courses had a different size and design that reduced comparability.

For these reasons, the results presented here should be viewed as but one attempt at integrating research article writing skills into an introductory course. Still, when combined with existing findings suggesting that parts of the article writing process can be successfully taught in an introductory course, I would argue that students new to the discipline learn a lot from and actually enjoy engaging in the work that political scientists do. Future work would do well to see whether the research article writing skills students learn in an introductory course translate into increased interest and improved performance in research methods or senior capstone courses, thus producing long-run benefits both to students and to the department as a whole. 


\section{References}

Bergbower, Matthew L. 2017. "When Are Students Ready for Research Methods? A Curriculum Mapping Argument for the Political Science Major." Journal of Political Science Education 13(2):200-210.

Bernstein, Jeffrey L. and Brooke Thomas Allen. 2013. "Overcoming Methods Anxiety: Qualitative First, Quantitative Next, Frequent Feedback Along the Way." Journal of Political Science Education 9(1):1-15.

Blings, Steffen and Sarah Maxey. 2017. "Teaching Students to Engage with Evidence: An Evaluation of Structured Writing and Classroom Discussion Strategies." Journal of Political Science Education 13(1):15-32.

Bob, Clifford. 2001. "A Question and an Argument: Enhancing Student Writing through Guided Research Assignments." PS: Political Science 6 Politics 34(3):653-655.

Bos, Angela L. and Monica C. Schneider. 2009. "Stepping around the Brick Wall: Overcoming Student Obstacles in Methods Courses." PS: Political Science 8 Politics 42(2):375383.

Carson, Susan and Eric S. Miller. 2013. "Introducing Primary Scientific Literature To FirstYear Undergraduate Researchers." CURQ on the Web 34(4):17-22.

Dickovick, J. Tyler. 2009. "Methods in the Madness: Integrative Approaches to Methodology in Introductory Comparative Politics." Journal of Political Science Education 5(2):138153.

Franklin, Daniel, Joseph Weinberg and Jason Reifler. 2014. "Teaching Writing and Critical Thinking in Large Political Science Classes." Journal of Political Science Education $10(2): 155-165$. 
Harrison, Melinda, David Dunbar, Lisa Ratmansky, Kimberly Boyd and David Lopatto. 2011. "Classroom-Based Science Research at the Introductory Level: Changes in Career Choices and Attitude." CBE-Life Sciences Education 10(3):279-286.

Hummer, Jill Abraham. 2014. "The Content and Integrative Component of Capstone Experiences: An Analysis of Political Science Undergraduate Programs." Journal of Political Science Education 10(2):222-242.

Ishiyama, John. 2002. "Does Early Participation in Undergraduate Research Benefit Social Science and Humanities Students?" College Student Journal 36(3):318-387.

Ishiyama, John and Marijke Breuning. 2003. "Does Participation in Undergraduate Research Affect Political Science Students?" Politics $\&$ Policy 31(1):163-180.

Ishiyama, John and Wendy L. Watson. 2014. "Using Computer-Based Writing Software to Facilitate Writing Assignments in Large Political Science Classes." Journal of Political Science Education 10(1):93-101.

Jordan, Tuajuanda C., Sandra H. Burnett, Susan Carson, Steven M. Caruso, Kari Clase, Randall J. DeJong, John J. Dennehy, Dee R. Denver, David Dunbar, Sarah C. R. Elgin, Ann M. Findley, Chris R. Gissendanner, Urszula P. Golebiewska, Nancy Guild, Grant A. Hartzog, Wendy H. Grillo, Gail P. Hollowell, Lee E. Hughes, Allison Johnson, Rodney A. King, Lynn O. Lewis, Wei Li, Frank Rosenzweig, Michael R. Rubin, Margaret S. Saha, James Sandoz, Christopher D. Shaffer, Barbara Taylor, Louise Temple, Edwin Vazquez, Vassie C. Ware, Lucia P. Barker, Kevin W. Bradley, Deborah Jacobs-Sera, Welkin H. Pope, Daniel A. Russell, Steven G. Cresawn, David Lopatto, Cheryl P. Bailey and Graham F. Hatfull. 2014. "A Broadly Implementable Research Course in Phage Discovery and Genomics for First-Year Undergraduate Students." mBio 5(1):1-8.

Leston-Bandeira, Cristina. 2013. "Methods Teaching through a Discipline Research-Oriented Approach." Politics 33(3):207-219. 
Medvedeva, Maria and Timothy Recuber. 2016. "Developing an Original Argument: A Strategy for College Writing." College Teaching 64(3):139-144.

Olsen, Jonathan and Anne Statham. 2005. "Critical Thinking in Political Science: Evidence from the Introductory Comparative Politics Course." Journal of Political Science Education 1(3):323-344.

Scheel, Elizabeth D. 2002. "Using Active Learning Projects to Teach Research Skills Throughout the Sociology Curriculum." Sociological Practice 4(2):145-170.

Sherman, Daniel J and Israel Waismel-Manor. 2003. "Get It in Writing: Using Politics to Teach Writing and Writing to Teach Politics." PS: Political Science 6 Politics 36(4):755757.

Siver, Christi, Seth W. Greenfest and G. Claire Haeg. 2016. "Are We Teaching Them Anything?: A Model for Measuring Methodology Skills in the Political Science Major." Journal of Political Science Education 12(2):186-199.

Sommers, Nancy and Laura Saltz. 2004. "The Novice as Expert: Writing the Freshman Year." College Composition and Communication 56(1):124.

Wenk, Laura and Loel Tronsky. 2011. "First-Year Students Benefit From Reading Primary Research Articles." Journal of College Science Teaching 40(4):60-67.

Williams, Michelle Hale, Kymberly Anne Goodson and W. Gary Howard. 2006. "Weighing the Research Paper Option: The Difference That Information Literacy Skills Can Make." PS: Political Science \& Politics 39(3):513-519.

Zeiser, Pamela A. 1999. "Teaching Process and Product: Crafing and Responding to Student Writing Assignments." PS: Political Science 6 Politics 32(3):593-595. 